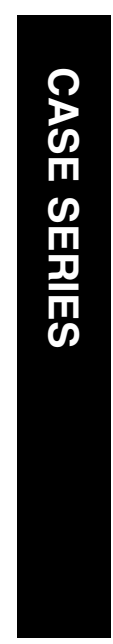

\section{Adalimumab for sight-threatening uveitis in Behçet's disease}

B Mushtaq', T Saeed', RD Situnayake ${ }^{2}$ and PI Murray'

\begin{abstract}
Aims To describe the clinical outcome of three patients with Behçet's disease maintained on infliximab who were switched to adalimumab therapy.

Methods Case note review. Main outcome measure was recurrence of uveitis.

Results All patients remained free of recurrence with stable visual acuities. Conclusions Adalimumab appears to maintain disease remission in Behçet's disease. Eye (2007) 21, 824-825; doi:10.1038/sj.eye.6702352; published online 7 April 2006
\end{abstract}

Keywords: uveitis; Behçet's disease; therapy; adalimumab

\footnotetext{
${ }^{1}$ Birmingham and Midland Eye Centre, Birmingham, UK

${ }^{2}$ City Hospital, Birmingham, UK
}

Correspondence: PI Murray, Academic Unit of Ophthalmology, Division of Immunity and Infection, University of Birmingham, Birmingham and Midland Eye Centre, Sandwell and West Birmingham Hospitals NHS Trust, City Hospital, Dudley Road,

Birmingham B18 7QU, UK Tel: +44121507 6851;

Fax: + 441215076853

E-mail: p.i.murray@

bham.ac.uk

Received: 28 November 2005

Accepted in revised form: 3 March 2006

Published online: 7 April 2006

\section{Introduction}

Infliximab (Remicade, Schering-Plough), a chimeric human murine monoclonal anti-TNF- $\alpha$ antibody, is a valuable treatment for sightthreatening uveitis in Behçet's disease (BD). ${ }^{1-6}$ It is effective in acute attacks, ${ }^{2}$ prevents relapses, ${ }^{3}$ and improves cystoid macular oedema (CMO). ${ }^{4}$ Infliximab requires day case hospital admission for intravenous infusions at 6-8-weekly intervals. As long-term treatment is frequently necessary in BD patients, this entails a large commitment in terms of time and travel for the patient. Recently, Adalimumab (Humira, Abbott), a fully humanised anti-TNF- $\alpha$ antibody has been available. It is given subcutaneously (s.c.) at 2-weekly intervals and is selfadministered, thus can be given at home.

We report three patients with sight threatening uveitis that fulfilled the ISG criteria for BD whose infliximab therapy was switched to adalimumab when they were in disease remission, and their uveitis has remained controlled after follow-up of 11, 21, and 24 months, respectively, at the time of writing. All patients tolerated the injections well with no adverse reactions. To our knowledge this is the first report of adalimumab therapy for the ocular complications of BD.

\section{Case reports}

\section{Patient 1}

A 41-year-old Caucasian female presented in 1997 with bilateral panuveitis and vision of $6 / 6$ in each eye. Over the next 6 years she had seven relapses of sight-threatening panuveitis requiring high dose intravenous (i.v.) and oral steroid, ciclosporin, methotrexate, intravenous cyclophosphamide, and laser photocoagulation. In March 2003, her vision was 6/18 right eye and 6/36 left eye with bilateral CMO. Infliximab i.v. infusions were started at $5 \mathrm{mg} / \mathrm{kg}$ given at 0 , $2,6,14,18$, and 26 weeks and then at 2-monthly intervals. Her $\mathrm{CMO}$ resolved and vision improved to 6/9 right eye and 6/18 left eye. She continued her oral steroid and methotrexate. In March 2005, after being stable for 21 months, she was switched to adalimumab $40 \mathrm{mg}$ s.c. 2 weekly as she was finding it difficult to attend hospital for the i.v. infusions. To date she remains in remission and is off her oral steroid.

\section{Patient 2 (Figure 1)}

A 28-year-old Caucasian male was referred in 1998 with a right panuveitis and hypopyon. His vision was HM right eye and 6/9 left eye. Over the next 4 years he had another eight attacks of sight-threatening panuveitis requiring high dose intravenous and oral steroid, ciclosporin, methotrexate, azathioprine, and i.v. cyclophosphamide. In January 2002, his vision was HM in each eye. Infliximab i.v. infusions were started at $5 \mathrm{mg} / \mathrm{kg}$, given at $0,2,6,14,18$, and 26 weeks. The left vision improved to $6 / 24$ and infliximab was stopped in September 2002 and he continued on oral steroid and azathioprine. After 2 months, the left uveitis recurred and vision dropped to HM. Infliximab was restarted at the 


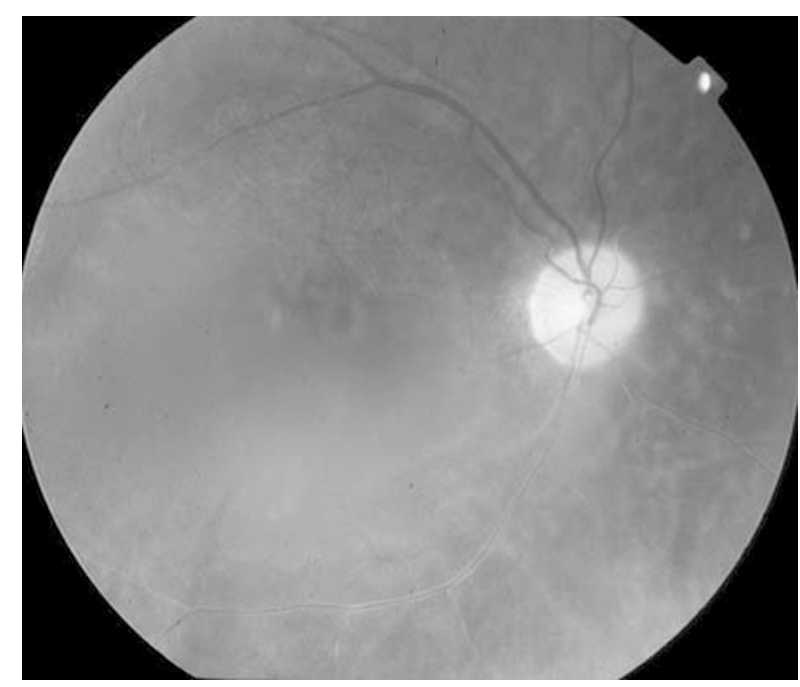

Figure 1 Fundus photograph of right eye of Patient 2.

same dose and continued at 2-monthly intervals and the vision returned to 6/36. In February 2004, he was switched to adalimumab as he was finding it difficult to attend hospital for i.v. infusions. The adalimumab was selfadministered as $40 \mathrm{mg}$ s.c. every 2 weeks along with the oral medication. To date, he remains in remission with stable vision of HM right eye and 6/36 left eye.

\section{Patient 3 (Figure 2)}

A 21-year-old Caucasian female was referred in 1994 with bilateral panuveitis and CMO with a vision of 6/12 in each eye. Over the next 7 years she had nine relapses of panuveitis requiring high dose i.v. and oral steroid, ciclosporin, methotrexate, azathioprine, mycophenolate mofetil, and i.v. cyclophosphamide. In July 2001, her vision was CF right eye, HM left eye and infliximab was started at $5 \mathrm{mg} / \mathrm{kg}$ as i.v. infusions at $0,2,6,14,18$, and 26 weeks and the left vision improved to $6 / 24$. Infliximab was stopped in June 2002 and she continued on oral steroid and mycophenolate. In December 2002, she had a relapse in the left eye with vision of CF. Infliximab was restarted at the same dose and continued at 2-monthly intervals and her left vision was stable at 6/36. In May 2004 , she was switched to adalimumab self-administered as $40 \mathrm{mg}$ s.c. every 2 weeks as she was finding difficulty in coping with the i.v. infusions. To date, she remains in remission on adalimumab and low dose alternate day steroid, having been weaned off her mycophenolate, with stable vision of $1 / 60$ right eye and 6/36 left eye.

\section{Comment}

All three patients had sight-threatening bilateral panuveitis from their $\mathrm{BD}$ that was poorly responsive to

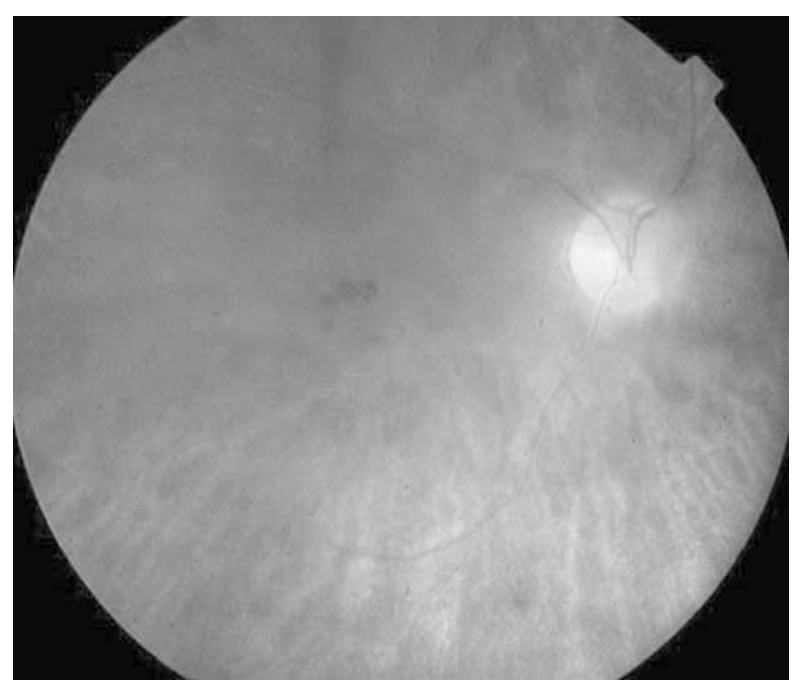

Figure 2 Fundus photograph of right eye of Patient 3.

conventional immunosuppression. The introduction of infliximab therapy stabilised their ocular disease, although in two patients they initially relapsed after the infliximab was stopped but improved after it was restarted. Switching to adalimumab has maintained their disease remission and prevented relapse. As the length of remission appears similar to $\mathrm{BD}$ patients who are on infliximab, switching to adalimumab appears to be a practical and convenient alternative without loss of efficacy.

\section{References}

1 Murray PI, Sivaraj RR. Anti-TNF- $\alpha$ therapy for uveitis: Behçet and beyond. Eye 2005; 19: 831-833.

2 Sfikakis PP, Theodossiadis PG, Katsiari CG, Kaklamanis P, Markomichelakis NN. Effect of infliximab on sightthreatening panuveitis in Behcet's disease. Lancet 2001; 358: 295-296.

3 Ohno S, Nakamura S, Hori S, Shimakawa M, Kawashima H, Mochizuki $\mathrm{M}$ et al. Efficacy, safety, and pharmacokinetics of multiple administration of infliximab in Behcet's disease with refractory uveoretinitis. J Rheumatol 2004; 31: 1362-1368.

4 Markomichelakis NN, Theodossiadis PG, Pantelia E, Papaefthimiou S, Theodossiadis GP, Sfikakis PP. Infliximab for chronic cystoid macular edema associated with uveitis. Am J Ophthalmol 2004; 138: 648-650.

5 Suhler EB, Smith JR, Wertheim MS, Lauer AK, Kurz DE, Pickard TD et al. A prospective trial of infliximab therapy for refractory uveitis: preliminary safety and efficacy outcomes. Arch Ophthalmol 2005; 123: 903-912.

6 Tugal-Tutkun I, Mudun A, Urgancioglu M, Kamali S, Kasapoglu E, Inanc $M$ et al. Efficacy of infliximab in the treatment of uveitis that is resistant to treatment with the combination of azathioprine, cyclosporine, and corticosteroids in Behcet's disease: an open-label trial. Arthr Rheum 2005; 52: 2478-2484. 